\title{
Fuchs's heterochromic cyclitis: a simultaneous bilateral fluorescein angiographic study of the iris
}

\author{
M. SAARI, I. VUORRE, AND H. NIEMINEN \\ From the University Eye Hospital, Oulu, Finland
}

SUMMARY Twelve patients with Fuchs's heterochromic cyclitis (FHC) were studied with simultaneous bilateral fluorescein angiography of the iris. The flow began a little earlier in the contralateral iris in 4 cases, and simultaneously in both irides in 8 cases. The radial iris vessels were narrow in 7 eyes with FHC and in the contralateral eyes of 2 elderly patients and of 1 patient with pigmentary retinal dystrophy and FHC. An ischaemic sector of the iris was seen in 6 eyes with FHC, neovascularisation of the iris in 8 eyes, and fluorescein leakage of the iris vessels was seen in all eyes with FHC. No neovascularisation of the iris occurred in the contralateral eyes, and only minimal fluorescein leakage was seen at the pupillary border of 5 contralateral eyes. The results support the hypothesis of vascular pathomechanism in FHC.

The clinical picture of Fuchs's heterochromic cyclitis (FHC) is well known (Fuchs, 1906; DukeElder and Perkins, 1966; Loewenfeld and Thompson, 1973). However, the aetiology of FHC is still in doubt (Duke-Elder and Perkins, 1966). An eye with FHC shows increased penetration of fluorescein from the blood stream into the anterior chamber (Amsler and Huber, 1946), and a small filiform haemorrhage may occur after paracentesis (Amsler and Verrey, 1946). A delicate rubeosis was noted histologically on the anterior surface of the iris and over the entire circumference of the angle in an eye with FHC (Perry et al., 1975). Fluorescein angiograms have demonstrated abnormal iris vessels with diffuse or patchy leakage of the dye from these vessels (Loewenfeld and Thompson, 1973). The purpose of this study was to evaluate further the vascular component in FHC. We report our observations on the circulation and vascular pattern of both irides in FHC studied by simultaneous bilateral fluorescein angiography of the anterior eye.

\section{Patients and methods}

Twelve patients with FHC were included in this study. Clinical characteristics of the first 11 patients (Cases 1-11) have been described earlier (Saari et al., 1977) and the case numbers of these patients

Address for reprints: Dr M. Saari, University Eye Hospital, Kajaanintie 50, SF-90220 Oulu 22, Finland correspond to those in the earlier study. The 12th patient in this study was a 39-year-old man with keratic precipitates, aqueous cells, complicated cataract, and stromal and pigment epithelial atrophy of the iris in the left eye, which was lighter in colour than the right eye with normal iris structure. He had pigmentary retinal dystrophy in both eyes.

Simultaneous bilateral angiography of the anterior eye (Helve and Nieminen, 1974) was performed on all patients. The photographic apparatus consisted of a Zeiss biomicroscope in which 2 motor-driven Nikon cameras were connected with one another. By means of prisms both eyes were photographed simultaneously. We used a pair of a Baird Atomic inteference filters B4 and as the barrier Kodak Wratten filters No 15. For each angiography we used $0.043 \mathrm{ml} / \mathrm{kg}$ of $10 \%$ sodium fluorescein. Photographs were taken at $\mathbf{0} \cdot 8$-second intervals. In each angiogram the beginning of the flow, the vascular pattern, the presence of ischaemic areas and neovascularisation, and the source of fluorescein leakage were recorded and compared with the findings of the contralateral eye.

\section{Results}

Simultaneous bilateral fluorescein angiographic findings from the iris in the eyes with FHC and in the contralateral eyes are shown in Table 1. In 3 patients (Cases 1-3) the flow in the anterior part 
Table 1 Simultaneous bilateral iris fluorescein angiographic findings in eyes with Fuchs's heterochromic cyclitis $(F H C)$ and in contralateral eyes

\begin{tabular}{|c|c|c|c|c|c|c|c|c|c|}
\hline $\begin{array}{l}\text { tCase } \\
\text { No. }\end{array}$ & Age & Eye & $\begin{array}{l}\text { Beginning of } \\
\text { flow }\end{array}$ & $\begin{array}{l}\text { Radial iris } \\
\text { vessels }\end{array}$ & $\begin{array}{l}\text { Ischaemic } \\
\text { sector }\end{array}$ & $\begin{array}{l}\text { Neo } \\
P P\end{array}$ & $\begin{array}{l}\text { cularisation } \\
C P\end{array}$ & $\begin{array}{l}\text { Fluo } \\
P P\end{array}$ & $\begin{array}{l}\text { cein leakage } \\
C P\end{array}$ \\
\hline 1 & 43 & $\begin{array}{l}\mathbf{R}(\mathrm{FHC}) \\
\mathbf{L}\end{array}$ & $\mathbf{L}$ & $\begin{array}{l}\text { Narrow, straightened } \\
\text { Normal }\end{array}$ & $\begin{array}{l}12 \\
\text { Coloboma }\end{array}$ & $\begin{array}{l}++ \\
-\end{array}$ & + & $\stackrel{++}{\mathbf{P B}}$ & $\begin{array}{l}+ \\
-\end{array}$ \\
\hline 2 & $\begin{array}{l}38 \\
59\end{array}$ & $\begin{array}{l}\text { R } \\
\text { L (FHC) } \\
\text { R (FHC) } \\
\text { L }\end{array}$ & $\mathbf{R}$ & $\begin{array}{l}\text { Normal } \\
\text { Narrow, straightened } \\
\text { Narrow, straightened } \\
\text { Normal }\end{array}$ & $\begin{array}{l}2-4 \\
\frac{1}{2} 9-\frac{1}{2} 10 \\
-\end{array}$ & $\begin{array}{l}- \\
++ \\
++ \\
-\end{array}$ & $\begin{array}{l}- \\
++ \\
++ \\
-\end{array}$ & $\begin{array}{l}\text { PB } \\
++ \\
++ \\
\text { PB }\end{array}$ & $\begin{array}{l}- \\
+t \\
+1 \\
-\end{array}$ \\
\hline 4 & 12 & $\begin{array}{l}\mathbf{R} \\
\mathbf{L} / \mathrm{FHC})\end{array}$ & $\mathbf{R}$ & $\begin{array}{l}\text { Normal } \\
\text { Normal }\end{array}$ & - & $\begin{array}{l}- \\
-\end{array}$ & - & $\bar{i}$ & - \\
\hline 5 & 15 & $\begin{array}{l}\text { R } \\
\mathbf{L}(\mathrm{FHC})\end{array}$ & $\mathbf{R}=\mathbf{L}$ & $\begin{array}{l}\text { Normal } \\
\text { Narrow, straightened }\end{array}$ & $\overline{3-4,6-7}$ & - & $\bar{t}$ & $\overline{+}$ & $\overline{1}$ \\
\hline 6 & 57 & $\underset{\mathrm{L}}{\mathrm{R}}(\mathrm{FHC})$ & $\mathbf{R}=\mathbf{L}$ & $\begin{array}{l}\text { Narrow } \\
\text { Narrow }\end{array}$ & - & $\begin{array}{l}- \\
-\end{array}$ & - & -1 & - \\
\hline 7 & 71 & $\begin{array}{l}\mathbf{R} \\
\mathbf{L}(\mathrm{FHC})\end{array}$ & $\mathbf{R}=\mathbf{L}$ & $\begin{array}{l}\text { Narrow } \\
\text { Narrow }\end{array}$ & - & - & $\overline{+}$ & $\bar{t}+$ & -1 \\
\hline 8 & 51 & $\begin{array}{l}\text { R } \\
L\end{array}$ & $\mathbf{R}=\mathbf{L}$ & $\begin{array}{l}\text { Normal } \\
\text { Normal }\end{array}$ & $\frac{1}{2} 3-6-10$ & - & - & $\begin{array}{l}\text { PB } \\
++\end{array}$ & - \\
\hline 9 & 35 & $\begin{array}{l}\mathbf{R} \\
\mathbf{L}(\mathrm{FHC})\end{array}$ & $\mathbf{R}=\mathbf{L}$ & $\begin{array}{l}\text { Normal } \\
\text { Normal }\end{array}$ & - & - & - & $\bar{t}$ & - \\
\hline 10 & 27 & $\begin{array}{l}\text { R } \\
\text { L (FHC) }\end{array}$ & $\mathbf{R}=\mathbf{L}$ & $\begin{array}{l}\text { Normal } \\
\text { Normal }\end{array}$ & - & - & $\begin{array}{l}- \\
+1\end{array}$ & $\begin{array}{l}\text { PB } \\
t-1 .\end{array}$ & $\overline{1}$ \\
\hline 11 & 42 & $\begin{array}{l}\mathbf{R}(\mathrm{FHC}) \\
\mathbf{L}\end{array}$ & $\mathbf{R}=\mathbf{L}$ & $\begin{array}{l}\text { Dilated } \\
\text { Normal }\end{array}$ & - & - & - & + & -1 \\
\hline 12 & 39 & $\begin{array}{l}\mathbf{R} \\
\mathbf{L}(\mathrm{FHC})\end{array}$ & $\mathbf{R}=\mathbf{L}$ & $\begin{array}{l}\text { Narrow } \\
\text { Narrow }\end{array}$ & $\overline{7-12-3}$ & - & $\begin{array}{l}- \\
+\end{array}$ & $\frac{-}{+}$ & $\bar{i}$ \\
\hline
\end{tabular}

$\mathbf{P P}=$ pupillary part of the iris. $\mathbf{C P}=$ ciliary part of the iris. $\mathbf{P B}=$ pupillary border. $++=$ extensive. $+=$ moderate. $-=$ absent

of the eye with FHC was slightly more delayed than in the contralateral eye (Fig. $1 A, B$ ). The eyes with FHC showed narrow, straightened radial iris vessels, an ischaemic iris sector, and neovascularisation with leakage in the pupillary and ciliary parts of the iris (Figs. 1-2), while the contralateral eyes showed normal vascular pattern of the iris without any ischaemia or neovascularisation (Fig. $1 B$ ) and only scanty fluorescein leakage at the pupillary border. In a 12-year-old boy (Case 4) the flow was slightly delayed in the anterior part of the eye with FHC, showing fluorescein leakage near the pupillary margin.

In 8 patients (Cases 5-12) the flow began simultaneously in the anterior part of both eyes (Fig. $3 A, B)$. In a 15 -year-old boy (Case 5) the eye with FHC showed narrow and straightened radial iris vessels, ischaemic iris sectors, moderate neovascularisation with leakage in the ciliary part of the iris and leakage of fluorescein in the pupillary part of the iris, whereas the angiographic findings in the contralateral iris were normal. In three patients (Cases 8-10) the breadth of the radial iris vessels was bilaterally normal; the iris of the eyes with
FHC showed moderate fluorescein leakage near the pupillary margin (Case 9), an ischaemic sector (Case 8), and moderate (Case 8) or extensive (Case 10) neovascularisation with extensive fluorescein leakage in the ciliary and pupillary parts of the iris (Figs. 3, 4). The angiographic findings in the contralateral iris were normal except for minimal fluorescein leakage at the pupillary border (Fig. $3 F, H)$ in 2 cases $(8,10)$. A 42-year-old man (Case 11) showed dilated radial iris vessels and moderate fluorescein leakage in the ciliary and pupillary parts of the iris in the eye with FHC; the angiographic findings in the contralateral iris were normal.

In 2 elderly patients the angiograms revealed narrow radial iris vessels in both eyes; extensive fluorescein leakage was seen in the pupillary part (Cases 6,7) and moderate fluorescein leakage in the ciliary part (Case 7) of the iris in the eye with FHC (Fig. 5). In the patient with pigmentary retinal dystrophy in both eyes (Case 12) the radial iris vessels were bilaterally narrow; the eye with FHC showed a large ischaemic iris sector, neovascularisation in the ciliary part, and fluorescein leakage in the pupillary and ciliary parts of the iris. 

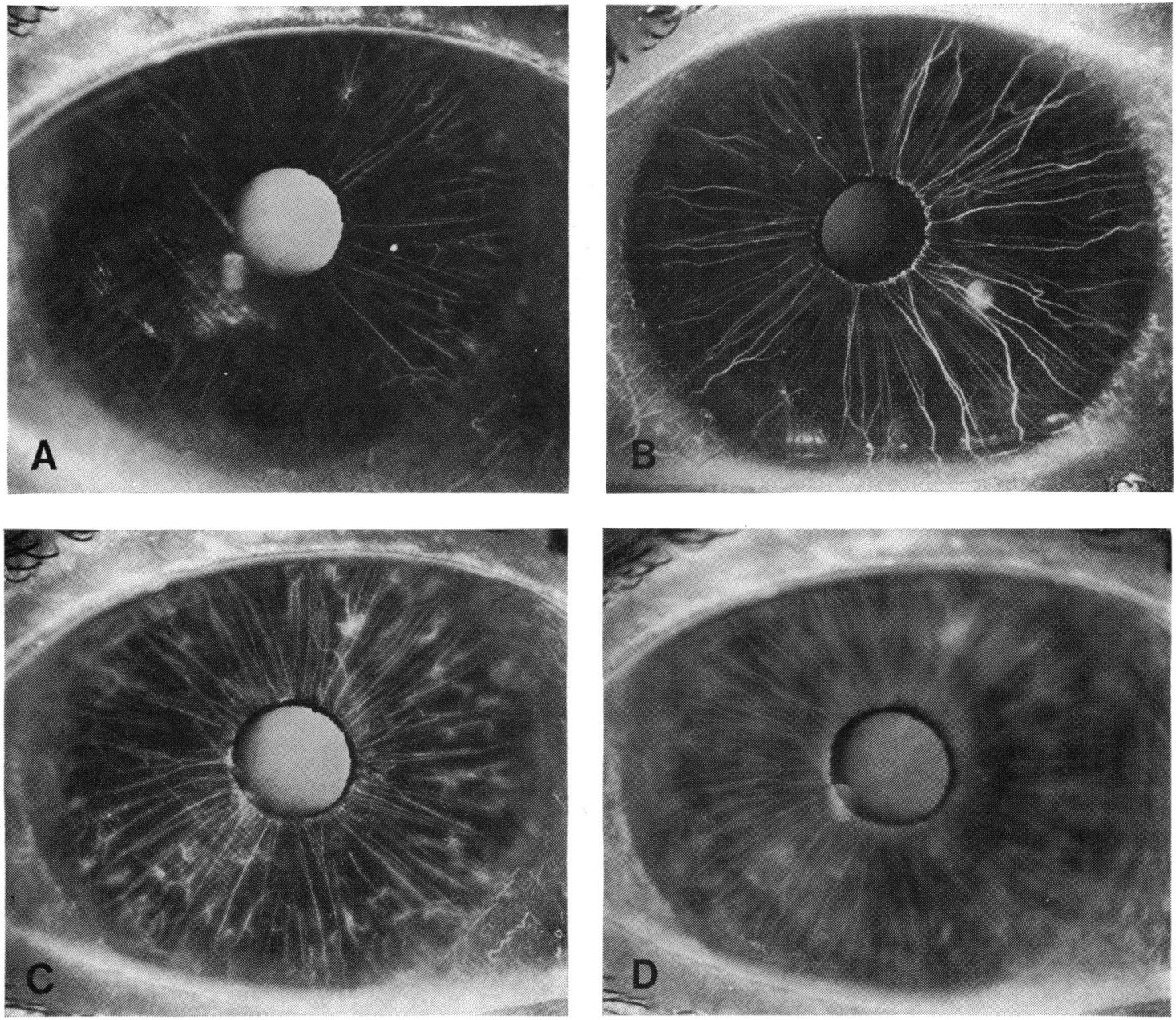

Fig. 1 (A, B) Simultaneous bilateral iris angiogram in FHC (Case 3) showing (A) affected eye with beginning of flow in radial iris arteries and in neovascular tufts of ciliary part, and (B) contralateral eye with normal iris vasculature in arteriovenous phase. (C, D) Affected eye (C) 6.4 s later showing narrow radial iris vessels and pronounced neovascularisation, and (D) $12 \mathrm{~s}$ later showing diffuse leakage

\section{Discussion}

Conventional iris angiograms in heterochromia may be difficult to interpret (Amalric, 1971). We used simultaneous bilateral iris angiography, which permits following the flow in both eyes and direct comparison of changes in the affected eye with the normal contralateral eye.

Simultaneous bilateral iris angiograms revealed in this study a slightly delayed iris circulation in 4 eyes and narrow radial iris vessels in 7 eyes with FHC. Histopathological studies have shown in FHC thickening and hyalinisation of the walls of the iris vessels, with proliferation of the endothelium reducing the lumen (Georgiades, 1964). We found ischaemic iris sectors as a sign of defective iris perfusion in 6 eyes with FHC. The slowing of iris circulation, narrow radial iris vessels, and ischaemic iris sectors seen in this study suggest that there is anterior segment ischaemia in eyes with FHC.

Simple biomicroscopic examination does not reveal neovascularisation of the iris in FHC (Campinchi, 1973). In this study angiograms revealed neovascularisation of the iris in 8 eyes with FHC. It was associated with an ischaemic iris sector in 6 cases and was most prominent in the eyes with narrow and straightened radial iris vessels. Thus anterior ocular ischaemia occurred in most eyes 

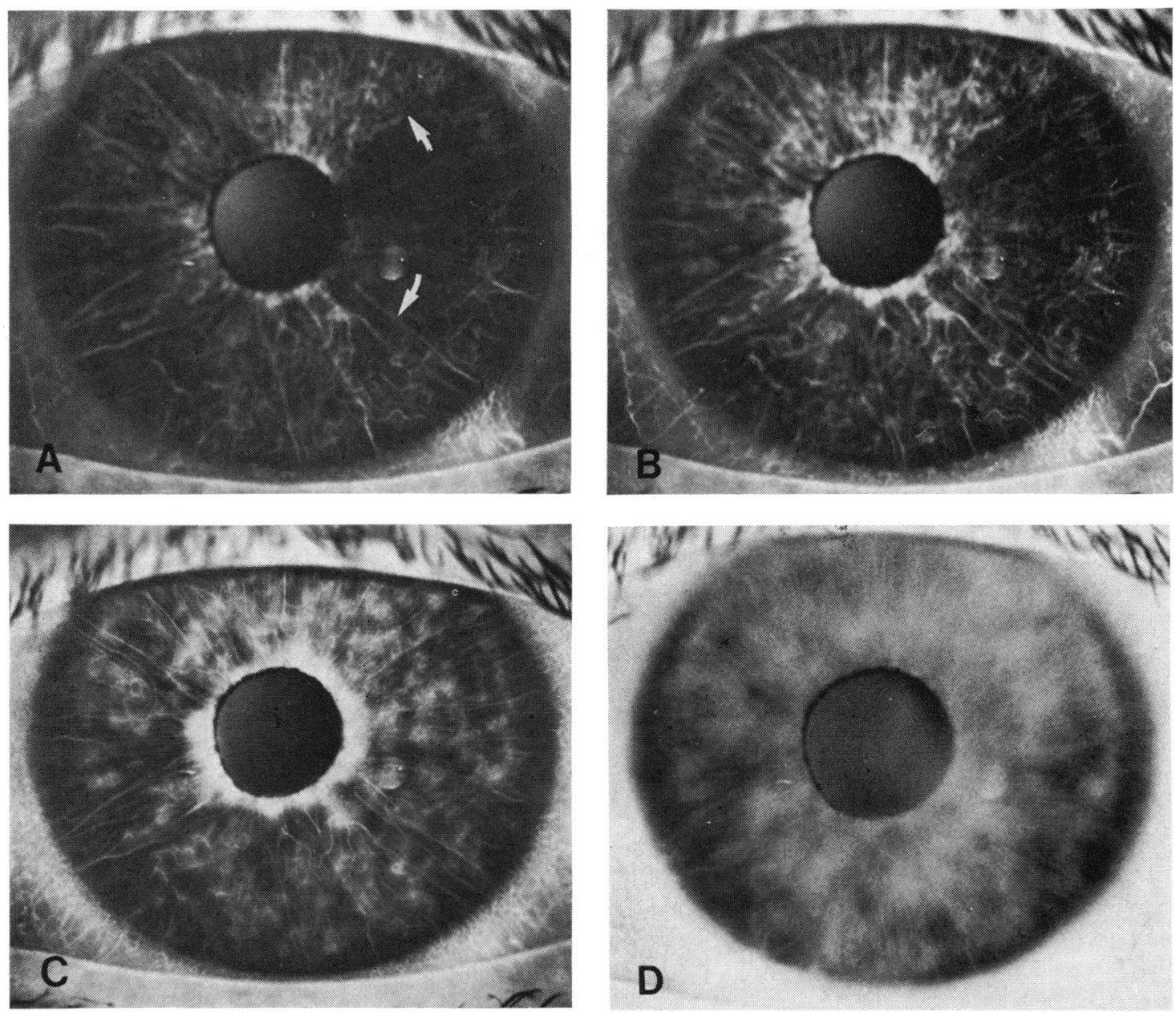

Fig. 2 Iris angiogram in FHC (Case 2). (A) Narrow radial iris arteries, ischaemic iris sector (arrows), and (B) extensive neovascularisation which $(\mathrm{C})$ leak fluorescein.

(D) Diffuse leakage in late phase

with FHC and neovascularisation of the iris.

In this study all eyes with FHC showed fluorescein leakage of the iris vessels. Leakage was most prominent at the site of newly-formed vessels, but it was also seen in 4 cases $(4,6,9,11)$ without neovascularisation. These findings are in good agreement with Amsler and Huber's (1946) observations on increased fluorescein permeability of blood-aqueous barrier in FHC. Sclerosis and hyalinisation of the iris vessels and neovascularisation may explain also the vascular fragility seen in FHC as filiform haemorrhage on puncture of the anterior chamber.

The angiographic findings in the iris in different eyes with FHC showed some variations. This may be explained on the basis of different age of the patients and different grade and stage of the disease.
The present results suggest that at the beginning of the disease there is leakage at the pupillary border and near the pupillary margin (Case 4). Later the radial iris vessels may become narrow and straightened with an ischaemic iris sector (Case 5), and in a late stage neovascularisation and extensive leakage are seen.

The present results support the hypothesis of a vascular pathomechanism in FHC. Flare and cells in the anterior chamber, iris atrophy with rubeosis, and cataract have been experimentally produced by occluding the long posterior or anterior ciliary arteries (Vassileva et al., 1975). We have seen cases in which signs similar to those in FHC have followed surgery for retinal detachment or squint, or recurrent necrotising rheumatic scleritis. The patho- 

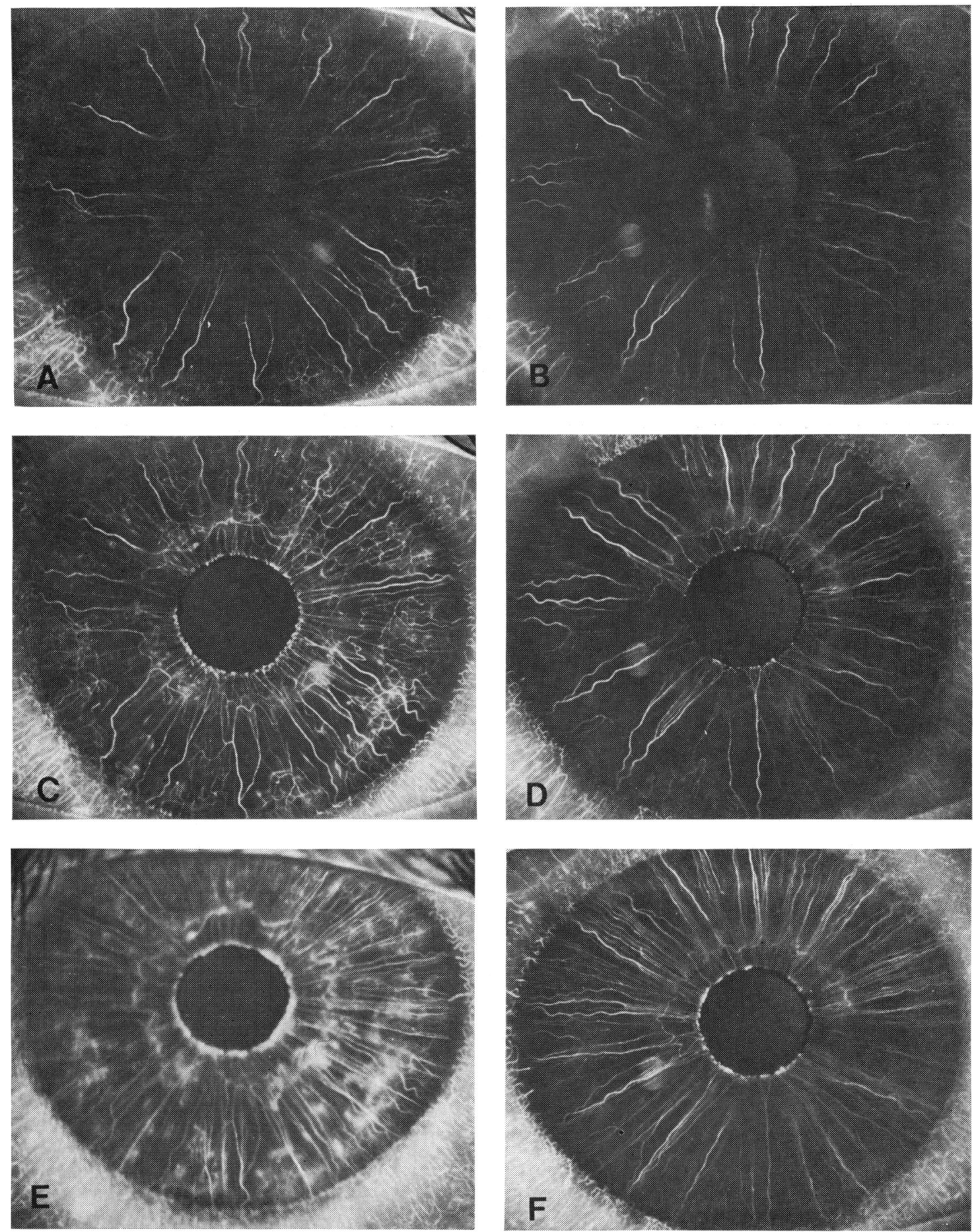

Fig. 3 Simultaneous bilateral iris angiogram in FHC (Case 10) (A, B) Arterial phase showing (A) affected iris with radial arteries of normal breadth and neovascularisation in ciliary part, and (B) contralateral iris with normal radial arteries. (C, D) Arteriovenous phase showing (C) affected iris with neovascularisation in pupillary and ciliary parts, and (D) contralateral iris with normal vascular pattern. (E, F) Late venous phase showing (E) affected iris with fluorescein leakage from new vessels, and $(\mathrm{F})$ contralateral iris with normal radial veins 

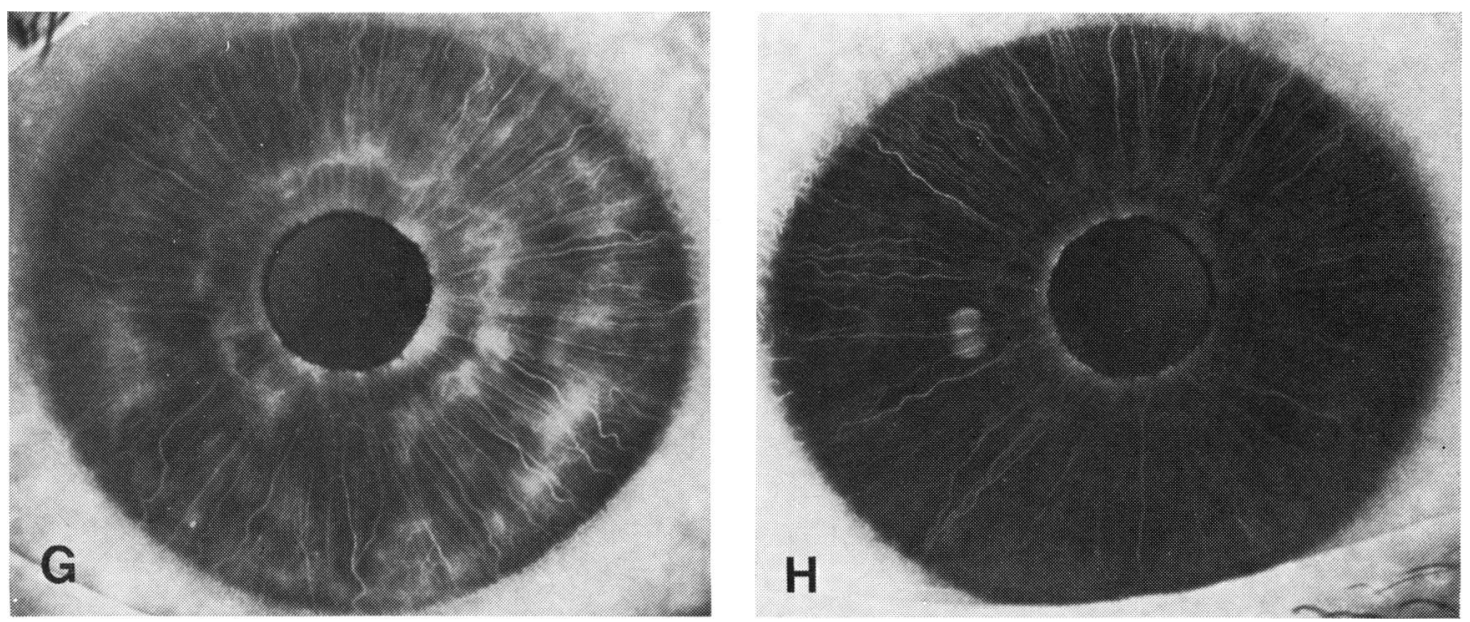

Fig. 3 (G, H) Late phase showing (G) affected iris with diffuse leakage, and $(\mathrm{H})$ contralateral iris with scanty leakage at pupillary border
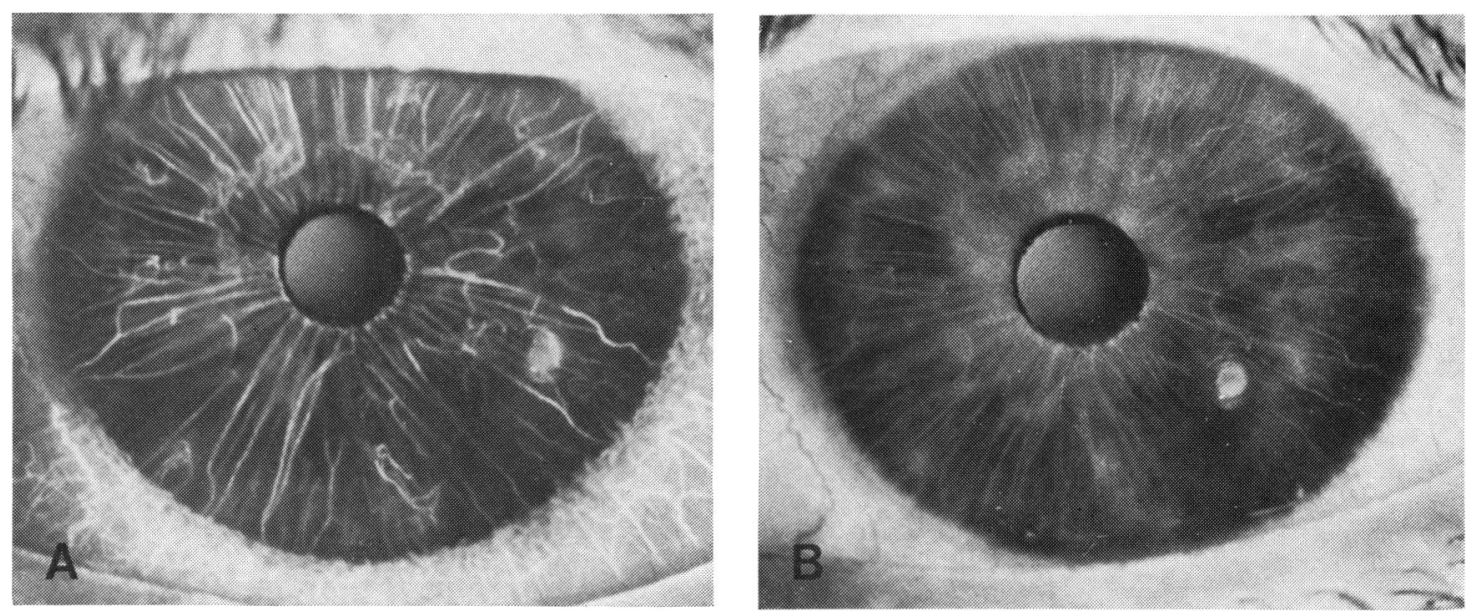

Fig. 4 Iris fluorescein angiogram in FHC (Case 8) showing (A) neovascularisation, and (B) $18.4 s$ later, leakage of dye from new vessels
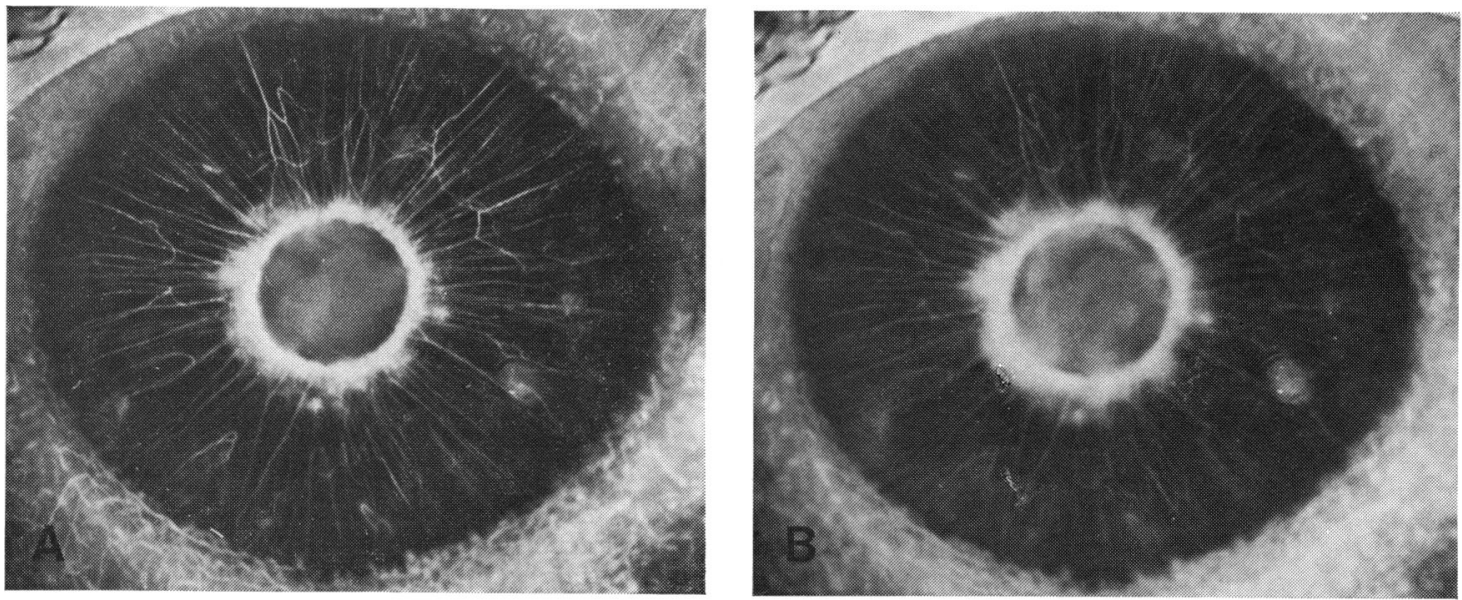

Fig. 5 Iris fluorescein angiogram in FHC (Case 7). (A) Narrow radial iris vessels and neovascularisation.

(B) $8.8 \mathrm{~s}$ later, extensive leakage around the pupil and leakage of dye from new vessels in ciliary part 
mechanism in these cases was obviously the interruption of the blood supply to the anterior segment. Because the iris vessels are purely sympathetically innervated (Ehringer and Falck, 1966), dysfunction of the sympathetic innervation of the iris on a hereditary basis may explain the pathogenesis in FHC.

This study was supported in part by the Medical Research Council for the Academy of Finland.

\section{References}

Amalric, P. (1971). Discussion of the paper L'Hétérochromie de l'iris by J. Michiels and J. P. Dernouchamps. Bulletins et mémoires de la Société Française d'Ophthalmologie, 84, 414-416.

Amsler, M., and Huber, A. (1946). Methodik und erste klinische Ergebnisse einer Funktionsprüfung der BlutKammerwasser-Schranke. Ophthalmologica, 111, 155-176.

Amsler, M., and Verrey, F. (1946). Hétérochromie de Fuchs et fragilité vasculaire. Ophthalmologica, 111, 178-181.

Campinchi, R. (1973). Fuchs' heterochromic uveitis. In Uveitis, Immunological and Allergic Phenomena, pp. 586597. Editors: R. Campinchi, J. P. Faure, E. Bloch-Michel, and J. Haut. Thomas: Springfield.
Duke-Elder, S., and Perkins, E. S. (1966). Diseases of the uveal tract. In System of Ophthalmology, Vol. IX, pp. 594-602. Editor: S. Duke-Elder. Kimpton: London.

Ehinger, B., and Falck, B. (1966). Concomitant adrenergic and parasympathetic fibres in the rat iris. Acta Physiologica Scandinavica, 67, 201-207.

Fuchs, E. (1906). Ueber Komplikationen der Heterochromie. Zeitschrift für Augenheilkunde, 15, 191-212.

Georgiades, G. (1964). Les lésions de l'iris hétérochromique en général. Bulletins et mémoires de la Société Française d'Ophthalmologie, 77, 465-487.

Helve, J., and Nieminen, H. (1974). Simultaneous bilateral fluorescein angiography of the anterior eye. Acta Ophthalmologica, Supplementum, 123, 134-135.

Loewenfeld, I. E., and Thompson, H. S. (1973). Fuchs's heterochromic cyclitis: a critical review of the literature. I. Clinical characteristics of the syndrome. Survey of Ophthalmology, 17, 394-457.

Perry, H. D., Yanoff, M., and Scheie, H. G. (1975). Rubeosis in Fuchs heterochromic iridocyclitis. Archives of Ophthalmology, 93, 337-339.

Saari, M., Vuorre, I., and Nieminen, H. (1978). Infra-red transillumination stereophotography of the iris in Fuchs's heterochromic cyclitis. British Journal of Ophthalmology, 62, 110-115.

Vassileva, P., Kottow, M., and Weigelin, E. (1975). Provoked iris ischaemia in the rabbit. I. Clinical and histopathological examinations. Albrecht von Graefes Archiv für klinische und experimentele Ophthalmologie, 196, 231-238. 